\title{
Alternative Professional Roles in Health Care Delivery: Leadership Patterns in Self-Help Groups
}

\author{
MARGARET YOAK \\ MARK CHESLER
}

\begin{abstract}
The increasing professionalization of health care delivery systems, improved client awareness, funding cutbacks, and an emphasis on voluntarism have led recipients of health services to turn increasingly to self-help groups. This article examines the leadership and organizational pattern of such groups, using a study of 43 self-help groups from around the U.S. whose members are parents of children with cancer. Three leadership patterns emerged: groups were independent and parent-led, were led by professionals, or had a shared leadership of parents and professionals. Data indicate that the professionally led groups were the smallest, least formal, and had the narrowest range of activities. The groups with shared leadership had the greatest longevity, tended most often to retain as members parents of deceased children. The authors conclude that such coalitions of clients and professionals are vital for ensuring proper service delivery at a time when health care systems will likely remain bureaucratic and public resources for professional care are being reduced.
\end{abstract}

The growth of professionalism in human service systems has increased the size and specialized roles of staff providing social and medical services to health care consumers. In addition to the proliferation of specialized categories of physicians and

The Journal of Applied Behavioral Science Volume 21, Number 4, Pages 427-444. Copyright $\mathbb{C} 1985$ by JAI Press, Inc. All rights of reproduction in any form reserved. ISSN: 0021-8863 nurses, health care professionals now include social workers, clinical nurse practitioners, recreational therapists, hospital teachers, child life workers, medical psychologists, and others (Begun, 1979; Eps-

Margaret Yoak is a health service development specialist in the St. Louis County Department of Community Health and Medical Care, 801 S. Brentwood Blvd., Clayton, Missouri 63105. Mark Chesler is a professor of sociology at the University of Michigan, Ann Arbor, Michigan 48109. 
tein, 1970). These specialized professions generate policy issues ranging from ethics, licensing, and regulation, through financing and differential access, to evaluation of services. Professional growth in health services, as in other human service systems, presents professionals, clients and consumers, and the general public with new problems and issues, along with new opportunities for improved and extended care.

Observers of professional service systems operating in the 1980s have begun to express concern for the level of public dissatisfaction with the nature and cost of such services, as well as with the vast bureaucracies through which services are often delivered. Stone (1983) identifies part of the problem as a "large gap between promise and performance," noting that ambitious and highly touted programs seldom generate "street-level" performance that matches their legislative or executive claims. In the European context, Bakker and Karel (1983) argue that the Dutch welfare state may have reached the limits of its possibilities, and that further advances in service cannot be produced by further professional development.

In addition, several observers note that trends toward professionalism and the bureaucratization of care have emerged in ways that exacerbate some of the least attractive aspects of each social form (Freidson, 1974; Lipsky, 1980; Prottas, 1979). Inasmuch as professionalism naturally segments roles and expertise, concentrating authority in the hands of one party to a relationship, it tends to disempower and reduce the skills used by those receiving professional services. Within the context of a large bureaucracy, office rules and roles make even more rigid these power and status distinctions, constraining the roles available both to professionals and to their clients. As Haug notes, "increasingly professionals are buttressed in their authority relations by virtue of their location in complex organizational settings" (1975, p. 201). As elites working within a structured hierarchy of power, professionals often seek to maintain their own status and authority, sometimes at the expense of service objectives (Larson, 1977; Ritzer, 1977).

Early scholarship on professionals and professionalism focused attention on attributes of status: professionals' advanced training, altruistic commitment to clients' welfare, special expertise, autonomy from client evaluation or review, and the resulting power to make decisions about others' lives and resources (Abbott, 1983; Friedson, 1970; Parsons, 1951; Roth, 1974). The bureaucratic form of service delivery exacerbates some of these tendencies, as when bureaucracy heightens and enforces divisions of labor among professionals and clients and marks their distinctive roles quite clearly, even to the point of their having different "uniforms." Rule-making authority is concentrated in expert and official hands, and expectations of obedience to these rules are transmitted downward through the organization. Haug (1976) offers one potent illustration of these combined effects: If a hospital requires patients to consult social workers to get financial assistance, receive information about their diseases and treatment, and make housing arrangements, it has defined the respective roles of patient and social worker in ways that add to the power already rooted in the knowledge implicit in professional status.

The bureaucratic hierarchy of roles adds administrative friction and inequality of status to the functional specialization of professionals' expertise (Stone, 1983). These trends also weaken the possibility of integrative and innovative service delivery. Some of the most talented and generous professionals often 
hold back on delivering service because of the great demands on their time and energy, conflicting loyalties to bureaucratic norms and to norms of client service, and their own defenses against burn out and malaise (Freudenberger, 1974; Maslach, 1976; Stone, 1983; Vachon, Lyall, \& Freeman, 1978).

These trends in bureaucratized professionalism have led to the continuation and refinement of what Haug and Sussman more than a decade ago called the "revolt of the client"' (1969). While current challenges may not be as heated as those that occurred during the heydays of the civil rights movement and the War on Poverty, disillusion with the assumptions of professionals' expertise, altruism, and moral authority continues. Many clients simply do not accept professionals' authority uncritically, demanding accountability or freedom to pursue their own choices of services and service providers (Rieff, 1971). Moreover, to the extent that professionals' moral authority is based upon special expertise, clients with an alternative claim to such expertise often prove quite vigorous in their challenges. Increased public education programs may provide many health care consumers, especially those with chronic diseases that they themselves must monitor, with an experiential knowledge base that cannot be monopolized by professionals and that, in some cases, may actually be far superior to that of professionals (Borkman, 1976; Haug, 1975). Finally, as the bureaucratized form of modern health care masses large numbers of clients into a few service settings, it facilitates patient contact and the development of a collective consciousness.

Under these circumstances, gaps in service delivery become more apparent and are strongly felt by many consumers. The failure to deliver on grand promises, inappropriate or inadequate services, or ser- vices defined solely by professionals' conceptions of clients' needs escalate clients' stress and discomfort. In the 1980s, such dissatisfaction with service delivery has been exacerbated by some of the same public policies designed to inhibit the ill effects of professionalism and bureaucratization. Cutbacks in federally funded programs, pressures for decentralizing service delivery, and an emphasis upon voluntary and nonstatutory services limit the availability and form of professional services even more severely.

Many of these issues are felt most strongly by people facing an extended health care crisis. Patients and families dealing with the shock of a serious illness, who are suddenly and chronically dependent upon a highly bureaucratized and specialized health care system, particularly need help and support. Some of their needs are successfully met by professional helping systems, but some are not, and not only because the professional caseload often is so overwhelming. Particularly strong needs may demand more of the professional provider, even as cutbacks and bureaucratized norms of segmented service provide less. Faced with the limitations of professional assistance, especially when rendered within bureaucratic organizations and cultures, many patients and their families seek help elsewhere, using informal networks of friends, family members, and neighborhood and business associates. Formal helping systems generally cannot provide the warm and intimate assistance found through an informal network (Froland, Pancoast, Chapman, \& Kimboto, 1981; Gourash, 1978; Kulka, Veroff, \& Douvan, 1979). Recently, increasing scholarly attention has been paid to the roles that informal helping systems, voluntary organizations, or nonstatutory care can play in filling such gaps and solving the dual problems of professional monopolies 
over service delivery and of service cutbacks (Fisher, Nadler, \& DePaulo, 1983; Gottlieb, 1981; Pancoast, Parker, \& Froland, 1983). One of the important forms of parallel or informal helping systems is the self-help group.

\section{SELF-HELP GROUPS AS ALTERNATIVE HUMAN SERVICE SYSTEMS}

Self-help groups are generally defined as "voluntary, small group structures for mutual aid and the accomplishment of a special purpose"' (Katz \& Bender, 1976, p. 9). In the health field, self-help groups typically comprise consumers or patients and their family members or advocates. Several recent reports suggest that the number of self-help groups in the health field is increasing rapidly, and that such groups are organized in many different medical settings to deal with a variety of illnesses.

Some researchers consider self-help groups in the health field a part of a social movement-a semi-organized challenge to professional and bureaucratic control over human services. Others see self-help groups as a means of stretching resources further in a time of scarcity and high demand (Back \& Taylor, 1976; Katz, 1981; Smith \& Pillemer, 1983; Steinman \& Traunstein, 1976). Groups of people with similar illnesses may help each other in ways that provide an alternative to highly bureaucratized forms of physical or psychosocial care. Oriented toward local communities or health clinics, self-help groups may help decentralize and personalize the large-scale, standardized social services available at secondary or tertiary care centers. Using highly personal, intimate, and peer-oriented norms of caring and exchange, they provide a different kind of help. In the current context of cutbacks in financial support for extended health services, especially in out-patient arenas, these voluntary efforts are attractive to consumers and providers alike.

Despite these potential or actual benefits, however, self-help groups exist on the margins of organized service provision. Medical practitioners and researchers often express concern about the potential dangers of nonprofessional voluntary efforts, and some even suggest ways in which such activities may threaten traditional forms of health care delivery (Tracy \& Gussow, 1976). Professionals' relations with these groups have been described both as collaborative (Borman, 1979; Lenrow \& Burch, 1981) and confrontational (Katz, 1981; Kleinman, Mantell, \& Alexander, 1976). Professionals have resources that can enhance these groups' counseling skills, information about diseases and treatments, leadership skills, and access to organizational resources, such as meeting rooms, mailing lists, and other staff members. Many professionals, however, do not clearly understand how they can be useful to self-help groups. Thus, some professional service providers who try to work with such groups take a positive, active stance-initiating groups or serving as leaders or managers, organizational consultants, program presenters, facilitators of group discussions, and referral agents for new members-while others approach self-help groups warily, concerned about antiprofessional attitudes, inappropriate emotional contagion, and violation of other patients' privacy or emotional integrity. Still other professionals quite deliberately resist or divert groups' efforts.

Unfortunately, research on self-help groups is fairly new, and research relying primarily on individual case studies and 
anecdotal evidence (Katz, 1981) has not helped clarify these issues. In fact, much of the research seems to display an "ad hoc and unsystematic quality" (Smith \& Pillemer, 1983, p. 207). Older studies have focused on gaining a greater understanding of what self-help groups do and developing descriptive typologies of groups' goals and activities (Katz \& Bender, 1976; Killilea, 1976; Levy, 1976). More recent efforts have included a focus on organizational aspects such as leadership, membership, formal structure, and institutional affiliation (Pilisuk \& Parks, 1980; Smith \& Pillemer, 1983). Beyond description, little systematic analysis has been conducted to guide a more generalized understanding of self-help groups and their distinctive dynamics or of professionals' roles in them.

In this article, we examine the different leadership roles professionals played in a sample of self-help groups of parents of children with cancer. We explicitly focus upon the organizational dynamics and activity patterns of these groups and explore various options for cooperation among professionals and parents. Because we believe that self-help groups formed around different illness categories may develop unique structures and activities, we first present a framework for understanding the particular problems of stress and social support in families of children with cancer.

\section{PSYCHOSOCIAL STRESSES AND THE SEARCH FOR SOCIAL SUPPORT}

Serious and chronic challenges to the wellbeing of children generate substantial stress for their parents. The medical situation of the child with cancer is by no means the only problem requiring resolution; many other psychosocial stresses are cre- ated by the complexities of this chronic and serious illness. ${ }^{1}$ Moreover, children with cancer often are treated in tertiary care centers, requiring the coordinated efforts of a range of medical specialists. Thus, unlike minor health problems-but like other complex diseases-childhood cancer requires the patient and family to deal with long-term psychosocial stress and with medical professionals within the context of a highly bureaucratic and technological care system. In the attempt to cope with psychological and institutional stress, one resource that many parents use is social support. Research indicates that social support can buffer individuals from the full impact of some forms of stress and can help them recover from or deal with others that are unavoidable (DiMatteo \& Hayes, 1981; Gottlieb, 1981; Pilisuk \& Froland, 1978). Formal and informal helping systems alike offer resources relevant to such stress; therefore, support may be sought from the formal helping system, from the medical and social service staff, and from a range of informal helpers, including nuclear and extended family members, friends and neighbors, and acquaintances from church, school, or work. However, because formal helpers sometimes exacerbate the stress experienced by parents of seriously ill children (Chesler \& Barbarin, 1984; Featherstone, 1980; Pizzo, 1983) and the stigma of cancer may create unique difficulties for the normal range of informal helpers (Sontag, 1979; Wortman \& Dunkel-Schetter, 1979), many parents of children with cancer reach out to a unique form of social support, a locally available self-help or mutual support group.

The literature on self-help groups, and our own studies, suggest that some processes at work in self-help groups cannot be duplicated either by competent professional helpers or by close and caring 
friends. The importance of talking with someone "who has been there," and who "knows what it is like" permits a unique depth of exchange and support. Moreover, the possibility of assisting someone else, of "giving back to others the help I received," reflects a reciprocal and mutually empowering helping relationship hard to develop in friendships and professional relationships. These forms of sharing are realized in self-help groups through many different group activities. For instance, Katz (1959) suggests that groups typically provide social support, shared feelings, information exchange, direct services, and a means to exert pressure for change in service delivery systems. Richardson (1983), Langston and Peterson (1982), Levy (1976), and Lieberman (1979) suggest similar activities, while Lipson (1982) additionally finds reference processes and increased consciousness. With special regard to groups formed by parents of children with cancer, various authors have reported or stressed educational or informational activities (M. Adams, 1978; Belle-Isle \& Conradt, 1979; Heffron, 1975; Kartha \& Ertel, 1976), the sharing of feelings and emotional support (D. Adams, 1979; Gilder, Buschman, Sitarz, \& Wolff, 1976; Kartha \& Ertel, 1976), a concern for social relations and friendship networks (Belle-Isle \& Conradt, 1979; Martinson, 1976), and the provision of direct services, fundraising programs, and attempts to create changes in the medical system (Gilder et al., 1976). Each of these group activities probably responds to different forms of stress and coping tasks faced by parents of children with cancer (Chesler \& Yoak, 1984).

\section{METHODS}

Our primary research aim was to study variations in professional roles within self-help groups of parents of children with cancer. A sample of 43 self-help or mutual support groups was identified from a national pool of more than 250 such groups made available by the Candlelighters Childhood Cancer Foundation (a national network of self-help groups of parents of children with cancer), children's medical centers, and other state and national organizations and programs. Groups were selected to achieve variation with respect to geography, characteristics of the treatment center or community base (insofar as these could be determined), and structured relationships among each group and professionals in its health care system. Although no way exists to verify whether the sample is representative of the numerical distribution of such groups across a variety of dimensions, our experience has convinced us that it does represent the range of parent groups organized to deal with the problems of childhood cancer.

At each site, we conducted and taped a series of intensive individual and group interviews with group members and with the professionals working with them. ${ }^{2}$ Group interviews were considered appropriate because we were interested in group and organizational-level rather than individual-level phenomena. Each interview lasted an average of one and onehalf hours, and the overall contact time for each group was one to two days. A total of 310 persons from 43 groups were interviewed, including 233 parents/ members, 22 social workers, 23 nurses, 12 doctors, and 20 "others," usually people in related helping professions who had worked with a group. Additional information was collected through several written instruments: an individual checklist (administered on site) regarding group activities and medical-system relations, and a follow-up package that gathered additional group-level information and indi- 
vidual responses regarding group participation and benefits.

Coders reviewed all of the tapes of group interviews and reconstructed these interviews in written form. The informants' responses to individual questions were combined with group documents and materials into a composite for each group, with general data coded to highlight key themes, such as group structure, activities, relations with community and medical systems, professional roles and role dilemmas, and other aspects of group operations. Variables created from these general themes were coded to provide categorical measures appropriate for quantitative manipulation.

Based on this study, the remainder of this article will present (1) a summary of findings as to the range and diversity in groups' structures, operating procedures, activities, and professional/member leadership patterns; (2) an analysis of the relationships among professional/member leadership patterns and aspects of group structures, operations, and activities; and (3) implications of these findings for understanding the role dilemmas professionals face as they work with self-help groups. We synthesize these findings in a discussion of the new forms of professional-parent partnerships or coalitions required by such groups.

\section{DESCRIPTIONS OF GROUP CHARACTERISTICS}

Descriptions of group structures and operations are based primarily on information gathered from on-site interviews with group members and associated professionals and on analysis of printed materials, such as brochures, newsletters, and bylaws. This information, summarized in Table 1, indicates that no one "type" of self-help group exists, even within the relatively narrow range of groups for parents of children with cancer.

\section{Structure and operations}

The groups in this sample were widely varied in structure, ranging from informal groups without officers or by-laws $(37 \%)$ to highly structured nonprofit organizations with considerable internal differentiation of tasks and functions (37\%). Size categories ranged from fewer than 20 active members (46\%) to more than 100 (21\%), with a third category of groups (33\%) serving a large nominal membership with a small active core of participants. Most of the self-help groups studied $(67 \%)$ were relatively young, although a substantial percentage were older than four and one-half years and a few groups had persisted more than eight years.

A unique issue related to these particular groups was whether the parents of children who had died of cancer would become or remain active. Although no group had a formal or written policy, group norms and expectations differ on this issue: $63 \%$ of the groups retained parents of deceased children, while the remaining $37 \%$ did not. Access and recruitment patterns also varied for these selfhelp groups; $43 \%$ of the groups relied solely on medical-system referrals to attract new members, while $57 \%$ combined such referrals with active outreach and personal contact by members.

\section{Activities}

The activities pursued by groups in this sample were quite varied; most groups engaged in more than one activity, although these varied in importance and emphasis from group to group. Formal emotional support, found in $70 \%$ of the groups in this sample, was a central activity for some groups and more pe- 
Table 1

Range and Diversity in Self-Help Group Structure, Operations, and Activities

\begin{tabular}{|c|c|c|c|}
\hline \multicolumn{2}{|r|}{ Structure and Operations } & \multicolumn{2}{|c|}{$(N=43)$} \\
\hline \multirow[t]{3}{*}{ Formal structure } & High (incorporated, differentiated) & & $7 \%$ \\
\hline & Intermediate (semi-formal) & & $6 \%$ \\
\hline & Low (informal gatherings) & & $7 \%$ \\
\hline \multirow[t]{3}{*}{ Size } & Large (large attendance and mailing list) & & $1 \%$ \\
\hline & Active core (small attendance, large mailing list) & & $3 \%$ \\
\hline & Small (small attendance and mailing list) & & $6 \%$ \\
\hline \multirow[t]{3}{*}{ Age } & Stage 1 ( 4.5 years or less $)$ & & $7 \%$ \\
\hline & Stage $2(4.5-8$ years $)$ & & $8 \%$ \\
\hline & Stage 3 (more than 8 years) & & $5 \%$ \\
\hline \multirow{2}{*}{$\begin{array}{l}\text { Retain parents as members } \\
\text { after child dies }\end{array}$} & Yes & & $3 \%$ \\
\hline & No & & $7 \%$ \\
\hline \multirow[t]{2}{*}{ Referral source $(N=42)$} & Medical systems only & & $3 \%$ \\
\hline & Personal contact/outreach by parents & & $7 \%$ \\
\hline & Activities & $(N$ & 43) \\
\hline \multirow{2}{*}{\multicolumn{2}{|c|}{ Formalized emotional support at meetings }} & Yes & $70 \%$ \\
\hline & & No & $30 \%$ \\
\hline \multirow{2}{*}{\multicolumn{2}{|c|}{ Information and education, such as speakers, movies }} & Yes & $74 \%$ \\
\hline & & No & $26 \%$ \\
\hline \multirow{2}{*}{\multicolumn{2}{|c|}{ Fund raising for organizational maintenance, service, or large projects }} & Yes & $70 \%$ \\
\hline & & No & $30 \%$ \\
\hline \multirow{2}{*}{\multicolumn{2}{|c|}{ Social events, such as parties, picnics, holiday events for children and parents }} & Yes & $81 \%$ \\
\hline & & No & $19 \%$ \\
\hline \multirow{2}{*}{\multicolumn{2}{|c|}{ Efforts to make changes in medical system to meet needs of families }} & Yes & $33 \%$ \\
\hline & & No & $67 \%$ \\
\hline \multirow{2}{*}{\multicolumn{2}{|c|}{ Vists by group to newly diagnosed families in the hospital }} & Yes & $42 \%$ \\
\hline & & No & $58 \%$ \\
\hline \multirow{2}{*}{\multicolumn{2}{|c|}{$\begin{array}{l}\text { One-to-one network of contact among parents outside meetings (telephone, } \\
\text { personal) }\end{array}$}} & Yes & $86 \%$ \\
\hline & & No & $14 \%$ \\
\hline
\end{tabular}

ripheral for others. Through this activity, groups provide an arena within which parents can share their joys and pains and discuss the problems they experience in dealing with childhood cancer. Information and education sessions (found in $74 \%$ of the groups) usually consisted of an outside speaker/expert addressing the group on some specialized aspect of the disease and its treatment. Groups also engaged in fund raising to support their activities (70\%); while most groups raised funds on a relatively small scale $(\$ 200-\$ 1,500$ annually), a few groups supported medical research and treatment or equipment purchases, with annual budgets as high as $\$ 60,000$.

Social activities were on the agenda for most groups $(81 \%)$, providing a setting within which people could gather informally, enjoy a sheltered time for both children and parents during which cancer was not perceived as a stigma, and engage in recreational programs, parties, and picnics. Some groups (33\%) worked to effect changes in the medical system, often collaborating with professionals to make the system more responsive to pa- 
tient and family needs; other groups advocated changes despite professional reluctance or resistance. Some groups (42\%) chose to offer support to newly diagnosed families in the hospital setting, while others left initial contacts to medical and social service professionals. Finally, many active parents established a practice of informal contact outside the group setting; $86 \%$ of the groups used telephone networks, personal visits, and other individual and family gatherings for informal social support.

\section{Leadership patterns: parent, professional, shared}

We divided the groups in this study into three categories: those in which parents are the sole leaders, those in which professionals provide primary leadership, and those in which members and professionals work closely together and share leadership functions.

Independent, parent-led groups are those in which parents of children with cancer organize, set agendas, and preside over group meetings. Forty-nine percent of the groups ( 22 of 43 groups) in the sample were independent groups in which parents constituted the leadership and most active membership. Professional activity in these groups ranged from having no consistent role to attending-but not planning or running-meetings. Professionals often offered support in other ways, such as by referring parents to the group, providing a liaison to the medical system, working with individual families to help meet their material or emotional needs, or helping secure resources for the group. In some cases, groups were independent because professionals were resistant to or simply not interested in parent groups, although those cases repre- sented a small minority. In most cases in this category, professionals were supportive but not very involved.

Shared-leadership groups are those in which parent-members are most central as leaders, but professionals also actively participate in the group's leadership. These professionals perceive themselves and are perceived as a support system to the parent leadership. Twenty-six percent (11 groups) demonstrated this shared or cooperative parent/professional leadership. Parents and professionals collaborated in planning and setting up meetings, keeping track of organizational business, and sharing in key decisions.

Professionally led groups are those in which the primary leadership functions of organizing, planning, and running or facilitating the group are performed by a professional, usually a member of the health-care system, such as a social worker, nurse, or psychologist. Twenty-six percent of the groups in our sample (11 groups) were led or run by professionals. In some cases, the professional demonstrated a desire to see parents take over more of the active leadership, but in most instances professionals considered their control beneficial to the group, providing parents with the opportunity for group participation while relieving them of the responsibility for group maintenance. Occasionally, parents in these groups voiced concern for their lack of control, but in most instances they seemed satisfied with the status quo. Some definitions of selfhelp groups might omit professionally led support groups from this population, but they were included in this sample and analysis for two reasons: First, because they make up one logical end point on the continuum of institutionally-engaged-toindependent parent groups, and, as such, 
can elucidate some of the dynamics in all groups. Second, the professionally led groups provide a useful contrast in comparative analysis of the independent and shared-leadership categories.

One must note that the assignment of groups to the above analytic categories is time bound. This study was cross sectional in nature, but groups experience transitions, as in their patterns of retaining parents of deceased children. In early stages of group development, if members' children are generally doing well, parents may exhibit a bias against associating with others whose children have died. If, however, the child of a member who is central to and greatly invested in the group should die, the group may change its prevailing attitude toward acceptance of parents of deceased children. Similarly, patterns in leadership and professional-parent relationships are susceptible to changes caused by staffing changes, membership turnover, or simply by conflict and accommodation in working relations. It is difficult to predict with any precision the degree of stability or change in any of these groups.

\section{Analysis of the relationship between leadership patterns and group characteristics}

Independent, parent-led groups tended to be high (48\%) and intermediate (38\%) in formal structure. Almost half of these groups were small $(43 \%)$, while another one-third were active core in size. Almost three-quarters $(71 \%)$ of the independent groups were young (Stage 1). About twothirds $(62 \%)$ of these groups retained group members whose children had died. Two-thirds of the independent groups combined personal outreach with medical-system referrals in recruiting mem- bers. Slightly more than half $(57 \%)$ engaged in support activities, while a strong majority engaged in information education, fund raising, social events, and oneto-one networking. More than one-third (38\%) engaged in efforts to make changes in the medical system, and about half (48\%) visited newly diagnosed families in the hospital.

Shared-leadership groups showed a somewhat greater tendency toward a formal structure than did the independent groups (55\% highly formalized), and they are more likely to be active core $(55 \%)$ or large $(27 \%)$ in size. Shared-leadership groups also tended to be the oldest in this sample, with 55\% in Stage 2 (four and one-half to eight years old). Most of these groups retained parents of deceased children $(91 \%)$. Moreover, they were quite similar to the independent groups in combining personal outreach with medicalsystem referrals $(70 \%)$ and in activities, engaging in only slightly more support and social activities, and somewhat less information dissemination, fund raising, and one-to-one networking. Of this sample, the shared-leadership groups most often were involved in making changes in the institutional system (46\%) and in visiting newly diagnosed families in the hospital (55\%).

The professionally led groups in this sample were all low in formal structure, and most were also small $(82 \%)$ and young $(91 \%)$. These findings confirm Stolberg and Cunningham's 1980 report that parent support groups are small and short-lived. Their data were gathered from medical professionals at 25 major children's cancer clinics throughout the nation, and undoubtedly reflect the limited reality of professionally led support groups. Most of the literature regarding 
Table 2

Self-Help Group Characteristics

in Relation to Professional, Independent, and Shared Leadership

\begin{tabular}{|c|c|c|c|c|}
\hline \multicolumn{2}{|c|}{ Structure and Operations } & \multirow{2}{*}{$\begin{array}{c}\begin{array}{c}\text { Professional } \\
(N=11)\end{array} \\
0 \%\end{array}$} & \multirow{2}{*}{$\begin{array}{c}\begin{array}{c}\text { Independent } \\
(N=21)\end{array} \\
48 \%\end{array}$} & \multirow{2}{*}{$\begin{array}{c}\begin{array}{c}\text { Shared } \\
(N=11)\end{array} \\
55 \%\end{array}$} \\
\hline Formal structure** & High & & & \\
\hline & Intermediate & 0 & 38 & 27 \\
\hline & Low & 100 & 14 & 18 \\
\hline \multirow[t]{3}{*}{ Size* } & Large & $9 \%$ & $24 \%$ & $27 \%$ \\
\hline & Active core & 9 & 33 & 55 \\
\hline & Small & 82 & 43 & 18 \\
\hline \multirow[t]{3}{*}{ Age* } & Stage 1 & $91 \%$ & $71 \%$ & $36 \%$ \\
\hline & Stage 2 & 9 & 24 & 55 \\
\hline & Stage 3 & 0 & 5 & 19 \\
\hline \multirow{2}{*}{ Retain PDC** } & Yes & $36 \%$ & $62 \%$ & $91 \%$ \\
\hline & No & 64 & 38 & 9 \\
\hline \multirow{2}{*}{ Referral Source $(N=42)$} & Medical system & $73 \%$ & $33 \%$ & 30 \\
\hline & Personal outreach & 27 & 67 & 70 \\
\hline Activities & & $\begin{array}{c}\text { Professional } \\
(N=11)\end{array}$ & $\begin{array}{l}\text { Independent } \\
(N=21)\end{array}$ & $\begin{array}{c}\text { Shared } \\
(N=11)\end{array}$ \\
\hline \multirow[t]{2}{*}{ Formal emotional support** } & Yes & $100 \%$ & $57 \%$ & $64 \%$ \\
\hline & No & 0 & 43 & 36 \\
\hline \multirow{2}{*}{ Information and education** } & Yes & $45 \%$ & $91 \%$ & $73 \%$ \\
\hline & No & 55 & 9 & 27 \\
\hline \multirow[t]{2}{*}{ Fund raising** } & Yes & $23 \%$ & $86 \%$ & $82 \%$ \\
\hline & No & 77 & 14 & 18 \\
\hline \multirow[t]{2}{*}{ Social } & Yes & $73 \%$ & $81 \%$ & $91 \%$ \\
\hline & No & 27 & 19 & 9 \\
\hline \multirow{2}{*}{ Making changes } & Yes & $9 \%$ & $38 \%$ & $45 \%$ \\
\hline & No & 91 & 62 & 55 \\
\hline \multirow[t]{2}{*}{ Hospital visits } & Yes & $18 \%$ & $48 \%$ & $55 \%$ \\
\hline & No & 82 & 52 & 45 \\
\hline \multirow[t]{2}{*}{ One-to-one network** } & Yes & $64 \%$ & $100 \%$ & $82 \%$ \\
\hline & No & 36 & 0 & 18 \\
\hline
\end{tabular}

Statistically significant at $p<.10^{*}$ or at $p<.05^{* *}$ using the chi square analysis. The small sample in this study, resulting in some cells having very few cases, calls for caution in generalizing from these results.

childhood cancer groups, written by and for professionals, concentrates on this sort of professional leadership pattern. Our findings suggest, however, that support groups led by parents themselves, or by parent-professional partnerships, are likely to be larger and to have longer periods of existence. Professionally led groups are considerably more likely than are the independent and shared-leadership groups to rely on the medical system alone for referrals $(73 \%)$. They are also less likely to retain as members parents whose children have died (only $36 \%$ ). These groups engaged in more formal emotional support activities and fewer of all other activities than did the independent and shared-leadership groups. 


\section{DISCUSSION: A COMPARISON OF PROFESSIONAL AND PARENT LEADERSHIP IN SELF-HELP GROUPS}

The most striking differences in Table 2 occur between the professionally led groups and the general category of parentled groups (both independent and sharedleadership forms). The professionally led groups were significantly less formal, smaller, and younger, did not as often involve parents of deceased children, and stressed emotional support activities, even to the exclusion of some other activities engaged in by member-led groups. Moreover, the professionally led groups were not as often engaged in such active functions as promoting changes in the system of medical care or providing outreach to newly diagnosed families.

The professionally led groups' greater involvement in formalized emotional support activities may be explained in terms of the dominance of leaders competent in that role, who define the parents' needs primarily in those terms. The prevalence of emotional support sessions, and their impact on group culture, helps define that activity as the core of these groups' existence. Professional dominance also may explain the almost exclusive reliance on medical-system referrals these groups experienced: Parents may have had no need for an alternative recruitment or referral system if professionals provided that resource. Moreover, this limitedbut often effective-referral system may also explain why these groups remained small. Finally, a small group operating with professional leadership, with a medically managed referral system, may not have felt the need to undertake networking activities or parent-led hospital visitation efforts.
Professionally led groups thus may reflect the way professionals define the needs of families whose children have cancer. According to our findings, they focus on emotional support, on sharing and ventilating feelings to alleviate the stresses of their childrens' illness. The more diverse-and often more taskoriented-activities of the parent-led groups may reflect the wider range of needs and priorities parents themselves see-perhaps a need to have an impact on the fight against childhood cancer, to make the medical system more humane, or to reach out to other parents and families in their own times of crisis. In turn, some professionals have claimed that such an emphasis on external activities reflects the parents' denial of emotional stress, unwillingness to deal with the deeper psychological issues in their lives, and an "acting out" or displacement of internal tension.

One example of the diversity or changing nature of parents' needs, at least as expressed by the parents, was reflected in the experience of parents whose children had died or achieved a long-term recovery. Many of these parents had moved from support-oriented interests to more task-oriented concerns, as when many became involved in fund raising for Ronald McDonald Houses. According to Table 2, they were not likely to find support for these concerns in professionally led groups, and thus may have created new and more independent organizations. Parents' desires to move on to other activities-while having nothing within the group to which they can move-may also contribute to the tendency of professionally led groups to fail to survive beyond their first few years.

Aside from their own predilections, professionals may face bureaucratic constraints in defining their roles with respect 
to these groups' activities. For instance, the institutional definition of professionals' roles may limit their provision of support to the immediate medical or psychosocial effects of treatment, and then only during a period of active care. Thus, assistance with task activities such as fund raising may be beyond the definition of the professional role. From this same institutional perspective, the lower retention of parents of deceased children in professionally led groups may be attributed to the health care system's classification of these parents as outside the professional's caseload or sphere of duty when their children are no longer in treatment. Such restrictions would naturally influence the norms, activities, and eventual composition of the support group offered as a professional service by a hospital.

\section{Shared leadership: the parent-professional coalition}

The shared-leadership groups reflected a close articulation between the professional service system and the parent groups, even as they maintained autonomy and direction by parents. Because this option represents an alternative to the traditional formulations of professional $v s$. parent leadership that have dominated the counseling and self-help literature, this form of organization is especially interesting.

The shared-leadership groups were similar in structure to the independent groups, and somewhat more likely to be active core in size and older in age. They were more likely to include parents of deceased children in their membership (91\%). The shared-leadership groups did not differ much from independent groups in most activity categories, though they did engage in slightly (though not signifi- cantly) more system-change activities and less one-to-one networking and support.

The varied approaches to organizational structure and activities represented in the shared-leadership groups may reflect the more creative efforts of innovative parent-professional teams. The greater longevity of these groups, combined with their increased tendency to include as members parents of deceased children, may reflect a greater stability of membership and a more open approach to parents who have different needs in the process of coping with childhood cancer. The surprising fact that a greater proportion of shared-leadership than independent groups worked for change in medical and social-service care may open a new perspective on the potential for fruitful collaboration between self-help groups and institutional systems. Smith and Pillemer (1983) cite the literature as providing evidence that "groups that exhibit strong ties to professionals are more likely to focus on individual change, and less on institutional or societal change" ( $p$. 225). Although the data reported here partly challenge that assumption, "control" and "dependence" rather than "strong ties" may be the key issue. The trend for professionally led groups to undertake such change efforts less often may result from the groups' dependence upon their staffs for leadership-and the staff's loyalty to the medical bureaucracy. The shared leadership groups' increased involvement in change activities may reflect both their lack of dependence upon their staffs and their continuing access to medical resources.

The combination of autonomy and interdependence reflected in the shared leadership groups suggests the relevance of a coalition model of organization and organizational leadership. The basic principle underlying coalitions is that of the 
coming together of two or more parties, typically those that previously were in conflict with one another, into a temporary collaborative effort that benefits all (Chesler, 1981; Hinckley, 1979). The underlying conflict here, of course, is defined by parents' and professionals' differentiated roles, status, and power in their forced interaction. As Froland et al. (1981) note, the attempt to combine formal and informal helping systems involves a "clashing of two cultures," a perspective evident in most writings on the nature of coalition building. When these cultural differences between helping systems are exacerbated by bureaucratic roles within the health care system, the conflicts are likely to be deeper and more lasting. In forming coalitions, all parties must wrestle with their prior experience, which has oriented them to respect traditional status distinctions and to retreat, under stress, to roles of dominance or subordination-in this case, to that of service provider and service recipient. One of the dangers of a coalition, as in other forms of cross-status collaboration, is that dominant groups may continue to coopt, covertly direct, or even dominate previously subordinate groups, albeit in less visible and therefore less objectionable ways (Kleinman, Mantell, \& Alexander, 1976).

The need to experiment with new institutional forms and new patterns of interaction leads to another common theme in recent discussions of self-help groups, that of new roles for professionals. Borman (1979) suggests that work with selfhelp groups calls for a new conceptualization of the professional role, one that is less controlling, moving "from a principal and solo role to a collaborative one", (p. 29):

\footnotetext{
...p professionals [supporting self-help groups] . . . were apparently a new breed,
}

not succumbing to traditional professional models. They may be representing a "paradigm shift" for many human service professionals. (p. 41)

Self-help groups can thus redefine the professional-client relationship:

\begin{abstract}
Both parties . . . must search for a new balance. Clients have expertise in their own experience of the problem; professionals have special supporting knowledge in the medical or welfare sphere. Relations between clients and social workers are redefined in the direction of equality in rights and status, more input by the client, and a restriction of " $\mathrm{ex}$ pert" domination. (Bakker \& Karel, 1983, pp. 176, 179-180)
\end{abstract}

Though the extent to which we can generalize from these data is limited, the results certainly confirm these authors' suggestions for developing new professional options for self-help and support groups. A coalition requires parties to modify the institutional definitions of their skills and abilities-and accompanying status and privileges - and to develop more peer-oriented ways of relating to one another. It involves recognizing the institutional basis for conflicts between professionals and parents, and not interpreting disagreements as indicators of personal hostility (i.e., "acting out" on the part of parents or "boorishness" on the part of professionals). A coalition between professionals and self-help groups requires reconceptualizing the helping role into that of "resource" to the indigenous leadership of the group, in which professionals foster independence rather than dependence, solicit parent expertise rather than present their own, and are willing to "let go" when members wish to take over. The solution is not for professionals to disappear; professionals have valuable resources to offer self-help groups. They may help groups get established, provide support and consultation 
on organizational matters, train parents for leadership roles, and perform ongoing service roles, such as sponsor, facilitator, referral source, and advocate/mediator with institutional systems (Chutis, 1983; Dory \& Reissman, 1982; Wollert \& Barron, 1983). In addition, professionals can be effective coalition partners by helping empower the group in the local medical community (Reinharz, 1981). Making changes in the health care system to place greater material resources in the group's hands is one example; another is publicizing the utility and legitimacy of self-help activities to other members of the medical staff and to community agencies (Chutis, 1983; Richardson, 1983).

A coalition has two or more sets of active parties, of course, and parent leaders in turn have critical roles to play in defining and supporting new professional options. Group leaders must sometimes take the initiative in helping professionals learn to use their resources in new ways and to support professionals' taking risks in the group's behalf. As with all coalitions, new channels of communication will need to cut across the different experiences and perspectives of group members and professionals, and effort and flexibility on both sides may be necessary to keep those channels open over time. Instead of retreating to anger and isolation, coalition members will have to train each other to relate effectively, despite their differences.

\section{CONCLUSIONS}

Mutual efforts to make a coalition work are especially vital, because professional health care systems are not likely to disappear or to become radically "deprofessionalized" in the near future. Neither are highly bureaucratic medical care organizations likely to alter their structural and cultural characteristics dramatically. At the same time, new and expanded services are required by families of children with cancer, just as public resources for professional care are being reduced. Parents of children with cancer and other serious and chronic diseases do not have the option of avoiding or doing without institutional systems and professional services; they must deal with the secondary and tertiary care facilities capable of providing the highly specialized and complex medical technology that saves children's lives. Major advances in life spans and cure rates for children can be traced in large part to the technology and professional care available primarily in highly bureaucratic treatment centers. No one anticipates jeopardizing these advances by extensive deprofessionalization or debureaucratization, nor can parents and families long do without psychosocial support services. At the same time, it is clear that parents of seriously ill children, as are other chronic medical consumers, are becoming more highly educated about diseases and their treatment and are escalating their demands for different kinds of medical and social service care. If we are to join the two worlds of care, and to make maximum use of both formal and informal helping systems, we must experiment with roles more suited to a coalition between professionals and consumers.

Together, professionals may learn new ways of interpreting their roles with selfhelp and support groups, while patients and their advocates may cultivate more positive and powerful relationships with professionals. But the health care bureaucracies that integrate them must also become more flexible in defining the roles of professionals and patients, professionals' relationships with patient- and parent-led groups, and patients' and parents' active roles in health care. If the 
health bureaucracy cannot support such roles, then the system that has created the need for a coalition will have sabotaged the likelihood of its existence. If support for such new options is forthcoming, or even if committed parents and professionals can create coalitions without such support, we may experience the benefits of innovative and adaptive ways of meeting the needs of people undergoing personal and family crises.

Self-help groups are prime examples of informal support systems that are semiautonomous or minimally dependent upon paid professional support. In contrast to professionally led support groups, or highly independent alternatives, the professional-parent coalition represented by shared-leadership self-help groups signals an important option for the future. Its continued growth and development presents us with a creative response to the bureaucratization and professionalization of modern health care. It also promises to supply local, voluntary energy to fill the gap created by cutbacks in federal and statutory services.

The coalition between professionals and consumers thus may address gaps in professional and bureaucratized medical care that occur on at least three levels: the micro level of providing compassionate and caring interpersonal support to patients and parents, the mezzo level of providing new resources for improved service delivery and changes in the structure of local medical care, and the macro level of jointly influencing the structure of health care delivery and financing in the United States.

\section{NOTES}

1. For a more detailed discussion of stress, social support, and parental coping with childhood cancer, see D. Adams (1979), Chesler and Yoak (1984), Coping with Cancer (1980), Futterman and
Hoffman (1973), Kellerman (1980), Ross (1978), Ross (1980), Schulman and Kupst (1980), Spinetta and Deasy-Spinetta (1981).

2. The research team was composed of a social psychologist-who is also a parent of an adolescent with cancer and founder of a self-help group-and an organizational sociologist with previous experience in community development and health service organization.

\section{REFERENCES}

Abbott, A. (1983). Professional ethics. American Journal of Sociology, 88(5), 855-885.

Adams, D. (1979). Childhood malignancy. In The psychosocial care of the child and his family. Springfield: C. C. Thomas.

Adams, M. (1978). Helping the parents of children with malignancy. The Journal of Pediatrics, 93(5), 734-738.

Back, K., \& Taylor, R. (1976). Self-help groups: Tool or symbol? Journal of Applied Behavioral Science, 12(3), 295-309.

Bakker, B., \& Karel, M. (1983). Self-help: Wolf or lamb? In D. Pancoast, P. Parker, \& C. Froland (Eds.), Social service delivery systems: An international annual (Vol. 6). Rediscovering selfhelp: Its role in social care. Beverly Hills: Sage.

Begun, J. (1979). The consequences of professionalization for health services delivery: Evidence from optometry. Journal of Health and Social Behavior, 20, 376-386.

Belle-Isle, J., \& Conradt, B. (1979). Report of a discussion group for parents of children with leukemia. Maternal-Child Nursing Journal, 8(1), 49-58.

Borkman, R. (1976, September). Experiential knowledge: A new concept for the analysis of self-help groups. Social Service Review, 50, 445456.

Borman, L. (1979). Characteristics of development and growth. In M. Lieberman \& L. Borman (Eds.), Self-help groups for coping with crisis: Origins, members, processes and impact. San Francisco: Jossey-Bass.

Chesler, M. (1981). Creating and maintaining interracial coalitions. In B. Bowser \& R. Hunt (Eds.), Impacts of racism on white Americans. Beverly Hills: Sage.

Chesler, M., \& Barbarin, O. (1984). Problems between the medical staff and parents of children with cancer. Health and Social Work, 9(1), 4965.

Chesler, M., \& Yoak, M. (1984). Self-help groups for families of children with cancer. In H. Roback 
(Ed.), Group intervention for medical-surgical patients and their families. New York: JosseyBass.

Chutis, L. (1983). Special roles of mental health professionals in self-help group development. Prevention in Human Services, 2(3), 65-73.

Coping with cancer. (1980). Bethesda, MD: U.S. Department of Health and Human Services, National Cancer Institute.

DiMatteo, M., \& Hayes, R. (1981). Social support and serious illiness. In B. Gottlieb (Ed.), Social networks and social support. Beverly Hills: Sage.

Dory, F., \& Reissman, F. (1982). Training professionals in organizing self-help groups. Citizen Participation, 3(3), 27-28.

Epstein, I. (1970). Professionalization, professionalism, and social worker radicalism. Journal of Health and Social Behavior, 11, 67-77.

Featherstone, H. (1980). A difference in the family. New York: Basic Books.

Fisher, J., Nadler, A., \& DePaulo, B. (Eds.). (1983). New directions in helping (Vol. 1). New York: Academic Press

Freidson, E. (1970). Profession of medicine. New York: Dodd and Mead.

Freidson, E. (1974). Dominant professions, bureaucracy, and client services. In Y. Hasenfeld \& R English (Eds.), Human service organizations. Ann Arbor: University of Michigan Press.

Freudenberger, H. (1974). Staff burn-out. Journal of Social Issues, 30, 159-165.

Froland, C., Pancoast, D., Chapman, N., \& Kimboto, P. (1981). Helping networks and human services. Beverly Hills: Sage.

Futterman, E., \& Hoffman, I. (1973). Crisis and adaptation in the families of fatally ill children. In J. Anthony \& C. Koupernick (Eds.), The child in his family: The impact of death and disease (Vol. 2.). New York: Wiley.

Gilder, R., Buschman, P., Sitarz, A., \& Wolff, J. (1976). Group therapy for parents of children with leukemia. American Journal of Psychotherapy, 30, 276-287.

Gottlieb, B. (Ed.) (1981). Social networks and social support. Beverly Hills: Sage.

Gourash, N. (1978). Help-seeking: A review of the literature. American Journal of Psychology, 6(5), 413-423.

Haug, M. (1975). The deprofessionalization of everyone? Sociological Focus, 8(3), 197-213.

Haug, M. (1976, Winter). The erosion of professional authority: A cross-cultural inquiry in the case of the physician. Health and Society, 83106.

Haug, M., \& Sussman, M. (1969). Professional au- tonomy and the revolt of the client. Social Problems, 17, 153-161.

Heffron, W. (1975). Group therapy sessions as part of treatment of children with cancer. In C. Pockedly (Ed.), Clinical management of cancer in children. Acton, MA: Science Group.

Hinckley, B. (1979). Twenty-one variables beyond the size of winning coalitions. Journal of Politics, 41(1), 192-212.

Kartha, M., \& Ertel, I. (1976). Short-term group therapy for mothers of leukemic children. Clinical Pediatrics, 15, 803-806.

Katz, A. (1959). Social adaptation in chronic illness: A study of hemophilia. American Journal of Public Health, 53, 1670-1671.

Katz, A. (1981). Self-help and mutual aid: An emerging social movement? Annual Review of Sociology, 7, 129-155.

Katz, A., \& Bender, E. (1976). Self-help groups in Western society: History and prospects. Journal of Applied Behavioral Science, 12(3), 265-282.

Kellerman, J. (Ed.). (1980). Psychological aspects of childhood cancer. Springfield, IL: C. C. Thomas.

Killilea, M. (1976). Mutual help organizations: Interpretations in the literature. In G. Caplan \& $\mathbf{M}$. Killilea (Eds.), Support systems and mutual help. New York: Grune and Stratton.

Kleinman, H., Mantell, J., \& Alexander, E. (1976). Collaboration and its discontents: The perils of partnership. Journal of Applied Behavioral Science, 12(3), 403-409.

Kulka, R., Veroff, J., \& Douvan, E. (1979). Social class and the use of professional help for personal problems: 1957 and 1976. Journal of Health and Social Behavior, 20(1), 2-17.

Langton, S., \& Petersen, J. (1982). What is selfhelp? Citizen Participation, 3(3), 3-4,7.

Larson, M. (1977). The rise of professionalism: $A$ sociological analysis. Berkeley: University of California Press.

Lenrow, S., \& Burch, R. (1981). Mutual aid or professional services: Opposing or complementary? In B. Gottlieb (Ed.), Social networks and social support. Beverly Hills: Sage.

Levy, L. (1976). Self-help groups: Types and psychological processes. Journal of Applied Behavioral Science, 12(3), 310-322.

Lieberman, M. (1979). Help-seeking and self-help groups. In L. Lieberman \& M. Borman (Eds.), Self-help groups for coping with crisis. San Francisco: Jossey-Bass.

Lipsky, M. (1980). Street-level bureaucracy: Dilemmas of the individual in public services. New York: Russell-Sage. 
Lipson, J. (1982). Effects of a support group on the emotional impact of Caesarean birth. Prevention in the Human Services, 1(3), 17-30.

Martinson, I. (1976). The child with leukemia: Parents help each other. American Journal of Nursing, 76(7), 1120-1122.

Maslach, C. (1976). Burned out. Human Behavior, 5, 17-22.

Pancoast, D., Parker, P., \& Froland, C. (1983). Social service delivery systems: An international annual (Vol. 6). Rediscovering self-help: Its role in social care. Beverly Hills: Sage.

Parsons, T. (1951). The social system. Glencoe, IL: The Free Press.

Pilisuk, M., \& Froland, C. (1978). Kinship, social networks, social support and health. Social Science and Medicine, 12B, 273-280.

Pilisuk, M., \& Parks, S. (1980). Structural dimensions of social support groups. The Journal of Psychology, 106, 157-177.

Pizzo, P. (1983). Parent to parent. Boston: Beacon Press.

Prottas, J. (1979). People-processing: The street level bureaucrat in public service bureaucracies. Lexington: Lexington Books.

Reinharz, S. (1981). The paradox of professional involvement in alternative settings. Journal of Alternative Human Services, 7, 21-24.

Richardson, A. (1983). English self-help: Varied patterns and practices. In D. Pancoast, P. Parker, \& C. Froland (Eds.), Social service delivery systems: An international annual (Vol. 6). Rediscovering self-help: Its Role in Social Care. Beverly Hills: Sage.

Rieff, R. (1971). The danger of the techni-pro: Democratizing the human service professions. Social Policy, 2, 62-64.

Ritzer, G. (1977). Working: Conflict and change. Englewood Cliffs, NJ: Prentice-Hall.

Ross, J. (1978). Social work intervention with families of children with cancer: The changing critical phases. Social Work in Health Care, 3, 257-272.

Ross, J. (1980). Childhood cancer: The parents, the patients, the professional. Issues in Comprehensive Pediatric Nursing, 4, 7-16.
Roth, J. (1974). Professionalism: The sociologist's decoy. Sociology of Work and Occupations, 1, 623.

Schulman, J., \& Kupst, M. (Eds.). (1980). The child with cancer. Springfield, IL: C. C. Thomas.

Smith, D., \& Pillemer, K. (1983). Self-help groups as social movement organizations: Social structure and social change. In L. Kriesberg (Ed.), Research in social movements, conflicts and change (Vol. 5). Greenwich, CT: JAI Press.

Sontag, S. (1979). Illness as metaphor. Cancer News, 33(1), 6-12.

Spinetta, J., \& Deasy-Spinetta, P. (1981). Living with childhood cancer. St. Louis: C. Mosely.

Steinman, R., \& Traunstein, D. (1976). Redefining deviance: The self-help challenge to the human services. Journal of Applied Behavioral Science, 12(3), 347-361.

Stolberg, A., \& Cunningham, J. (1980). Support groups for parents of leukemic children. In J. Schulman \& M. Kupst (Eds.), The child with cancer. Springfield, IL: C. C. Thomas.

Stone, C. (1983). Whither the welfare state? Professionalization, bureaucracy, and the market alternative. Ethics, 93, 588-595.

Tracy, C., \& Gussow, Z. (1976). Self-help health groups: A grass roots response to a need for services. Journal of Applied Behavioral Science, 12(3), 381-397.

Vachon, M., Lyall, W., \& Freeman, S. (1978). Measurement and management of stress in health professionals working with advanced cancer patients. Death Education, 1, 365-375.

Wollert, R., \& Barron, N. (1983). Avenues of collaboration. In D. Pancoast, P. Parker, \& C. Froland (Eds.), Social service delivery systems: An international annual (Vol. 6). Rediscovering self-help: Its role in social care. Beverly Hills: Sage.

Wortman, C., \& Dunkel-Schetter, C. (1979). Interpersonal relationships and cancer: A theoretical analysis. Journal of Social Issues, 35(1), 120155. 